recer vinculada a controles y orientaciones que llegan a condicionar la objetividad de nuestros objetivos docentes".

Se consideró también que el aumento de derechos de matrícula y de la enseñanza, que constituye "lo esencial de nuestros recursos", está necesariamente ligado al desarrollo económico de cada lugar y no puede hacernos autosuficientes sin correr el riesgo de convertir nuestras escuelas en instituciones elitorias y clasistas.
"Estas consideraciones llevan necesariamente a plantear la responsabilidad eclesial, punto de partida de la acción educativa que se cumple en nuestras instituciones. En este sentido, las Escuelas de Periodismo deben estudiar sin demora las fórmulas adecuadas para solventar sus necesidades materiales $\mathrm{y}$, sin olvidar que ellas deben resolverse ante todo con medios locales, estructuras proyectos que puedan lograr asistencia financiera de las Organizaciones Católicas Pertinen. tes".

\title{
SEMINARIO EN SAN JOSE Hacia un cambio en el carnpo de la Comunicación
}

"E1 papel socio-político de los Medios de Comunicación Colectiva para la Sociedad de Cambios en América Latina" fue el tema principal del So minraiø que, bajo la organización del Instituto Latinoamericano de Investigaciones Sociales, de la "CEDAL", de la fundación" Frederich Ebert y la CIES. PAL, se realizó en San José de Costa Rica, desde el 19 hasta el 25 de noviembre de 1972.

Entre los numerosos asistentes, en su mayor parte latînoamericanos y europeos, estuvieron Armando Mattelart, Peter Shenkel, Boris Van Wanter. CIESPAL fue represenfada por su Director, doctor Gonzalo ' Córdova, y el Jefe del Departamento Técnico, señor Marco Ordóñez.

Se hi o un análisis de los medios de comunicación colectiva, considerando que juegan un papel trascendente, que se torna aún más crítico - el momento actual "en que la confrontación entre las viejas y las nuevas fuerzas ha devenido muy aguda $y$ en que la mayoría de las sociedades latinoamericanas pug an por alcanzar un despegue auténtico". Los medios de comunicación, se dijo, tiener in- fluencia en la defensa de las ideologías y patrones de comportamiento impuestos por las clases dominantes.

Con referencia a los grupos propietarios, los participantes señalaron, según el documento final, que "forman"', en su gran mayoría, parte integral de las fuerzas económicas dominantes y se encuentran, por lo general, estrechamente vinculados a los mandos del Poder Polítcio y hegemónico".

"Estos grupos -añade- utilizan los medios de comunicación, fundamentalmente para dos objetivos vinculados entre sf: por una parte, como vehículos de difusión de la ideología de dominación cuyo fin es el mantenimiento del status quo en lo económico $y_{n}$ por otra parte, como instrumentos de promoción de consumos para el desarrollo de un sistema capitalista de mercado.

Sobre el comunicador, el documento considera que "en las actuales circunstancias suele cumplir en América Latina un papel supeditado ideológica, política, económica y culturalmente a los inte ses de los pro. pietarios. Se encuentra sometido a 
una censura abierta o encubierta y en la mayoría de los países a una auto. censura institucionalizada que le impide actuar como vocero de los intere. ses populares y como agente social de cambio, que es el verdadero rol que debe jugar en nuestras sociedades dependientes".

Por otra parte, se señaló que "en todos los países latinoamericanos existe un alto' grado de dependencia de los medios de comunicación de los servicios de información que monopolizan las grandes agencias internacionales". Más aún, se consideró que "el problema reviste mayor gravedad, ya que el monopolio no se limita al flujo de noticias desde el exterior sino se refiere también a los flujos de noticias dentro de la región y hasta dentro de los países y desde la región a otras áreas del mundo".

Respecto a la "función .ideológica de los medios" se analizaron sus objetivos -sostener la estructura de poder político, para consolidar el orden vigente, por ejemplo-, de los sistemas utilizados y de sus posibles consecuencias.

Entre otras cosas se estimó que "el desarrollo de las modernas tecnologías de comunicación (satélites videos casetes, rayos laser, televisión por cable) reclutan un nuevo público consumidor y amplían el campo de acción de la invasión cultural".

Al final se aprobó "una contrarrespuesta", a base de los siguientes puntos:

-La transformación de los medios de comunicación no es un mero problema técnico. Está íntimamente vinculado con el proyecto político y las estrategias y tácticas propias de las fuerzas de cambio;

-El ritmo y las formas de transformación dependen de los niveles de lucha y de conciencia alcanzados por las masas en la práctica política.
-La transformación radical del esquema de comunicación implica considerar el fenómeno comunicativo como un modo integral de producir mensajes. Sin embargo, los diferen: tes niveles de enfrentamiento determinan tácticas diferentes susceptibles de afectar, más o menos, este sistema total;

-Solamente partiendo del principio de que la comunicación es un problema político se puede encarar la misión revolucionaria de la comunica. ción como un medio más de movilizar a las masas a partir de su práctica cotidiana;

"Un' nuevo enfoque de la investigación dice el documento debe necesariamente seguir una camino antropológico-político y apartarse de los esquemas del empirismo. ' Es en esta perspectiva que toman su. verdadera dimensión los estudios sobre la estructura de poder de los medios".

\section{"UN EJEMPLO"}

Luego de sus asistencia al último Curso Internacional de Periodismo organizado por CIESPAL, el periodista venezolano Néstor Hernández Martín, Jefe de Redacción de "El Carabobeño", tuvo frases de elogio para el Centro.

Más aún, hizo una insinuación pública: "Las instituciones gubernamentales y privadas, muchas de las cuales son beneficiadas por el trabajo. de los periodistas, deberían imitar la iniciativa de la Asamblea Constituyente de Carabobo, única institución del país que concede dos becas anualmente a profesionales de la prensa para que viajen. a Quito a seguir los cursos de perfeccionamiento en periodismo que dicta CIESPAL".

"Los periodistas tienen que estar al día en los adelantos que registran vertiginosamente las Ciencias de la Información", añadió. 